\title{
Metodologías inductivas interculturales para una pedagogía decolonial
}

\author{
Inductive intercultural methodologies for \\ a decolonial pedagogy
}

\author{
Luz María Moreno Medrano* \\ GuSTAVo CoRRAl GuILlÉ**
}

Este artículo hace una propuesta de metodologías inductivas interculturales cuyo objetivo es poner al centro las voces de los actores principales de los procesos sociales de transformación. De esta manera, métodos no convencionales como fotografías de autoría infantil, fotovoz y mapas vivos son algunas alternativas para decolonizar la pedagogía tradicional a fin de alcanzar una intercomprensión y detonar el diálogo. Este trabajo se basa, en gran parte, en dos proyectos que surgen "desde abajo", desde los actores mismos, en estrecha colaboración entre educadores indígenas, niños, niñas y académicos, y que han recurrido a esas metodologías y se analiza su posible valor. Como demuestra este artículo, su uso va más allá de una posible estrategia de investigación, pues son también herramientas detonadoras de nuevas prácticas educativas que visibilizan otras formas de entender el mundo.

The purpose of this paper is to discuss and highlight intercultural inductive methodologies with the aim of giving voice to lead actors in the social transformation processes. In this way, non-conventional methods such as childrenauthored photography, photovoice and living maps are some alternatives to decolonize traditional pedagogies in order to reach a cross-comprehension and to foster dialogue. The paper is largely based on two projects that come "from below", from the actors themselves, in close collaboration between indigenous educators, children and academics. We discuss how these projects have turned to such methodologies and analyze their possible value, not only as a research strategy but also as a useful tool for fostering new educational practices in order to make visible other ways of understanding the world.

\author{
Palabras clave: \\ decolonización, \\ pedagogías \\ decoloniales, \\ educación \\ intercultural, \\ educación \\ inductiva
}

Keywords:

decolonization, decolonial pedagogies, intercultural education, inductive education

Recibido: 1 de septiembre de 2018.| Aceptado para su publicación: 7 de enero de 2019. Recuperado de: https://sinectica.iteso.mx/index.php/SINECTICA/article/view/910 DOI: 10.31391/S2007-7033(2019)0052-003

\footnotetext{
* Doctora en Sociología de la Educación por la Universidad de Cambridge. Profesora e investigadora en el Departamento de Educación de la Universidad Iberoamericana y coordinadora de la licenciatura en Pedagogía. Líneas de investigación: educación e interculturalidad. Correo electrónico: luzmaria.moreno@ibero.mx/http://orcid. org/0000-0002-0792-3479

** Doctor en Historia de la Ciencia por la Universidad Autónoma de Barcelona. Asistente de investigación en el proyecto Milpas Educativas, coordinado por el CIESAS y la Universidad Iberoamericana. Líneas de investigación: educación e interculturalidad. Correo electrónico: gustavo.corral@gmail.com/http://orcid.org/0000-0003-1004-6961
} 


\section{INTRODUCCIÓN}

T as pedagogías decolonizadoras abren nuevas posibilidades para avanzar en las reflexiones de otros modos posibles de conocer (Walsh, 2013a) y "sentipensar" (Esteva, 2015; Walsh, 2013b). Ahora el reto es saber cómo construir, desde abajo y de manera colaborativa, otros métodos que sean más significativos y que permitan espacios para entender modos alternos de conocer otros mundos.

La educación intercultural ha tenido grandes avances en las últimas décadas en México (Bertely, 2013; Dietz, 2003); sin embargo, no ha logrado todavía alejarse de una visión folclorizante de la cultura para lograr, por un lado, conocer otras formas de acercarse al conocimiento que no son las de las culturas dominantes y, por otro, problematizar las inequidades de poder, el racismo y la discriminación. La educación intercultural sin este elemento se ve limitada por una visión romántica y que muchas veces vuelve esencial las diferencias y las limita a sus características más visibles, como la vestimenta tradicional, la comida y las artesanías. La necesidad de construir una interculturalidad crítica (Fornet-Betancourt, 2000; García \& García, 2014; Gasché, 2010) es una tarea de investigadores, activistas, diseñadores de políticas públicas y demás actores sociales que buscan una sociedad más justa y equitativa.

En el campo de la psicología, las metodologías participativas en investigación se han utilizado ampliamente con fines diagnósticos, y dan importancia al color, la forma, la ubicación y otros elementos para evaluar la personalidad del niño, así como su situación emocional respecto a sus grupos más cercanos, como la familia o la escuela. Esta aproximación sigue siendo, en nuestra perspectiva, una manera de etiquetar, desde el punto de vista del déficit, expresiones culturales y formas de vida que suelen no ser comprendidas por la sociedad dominante. El reto de probar metodologías que permitan a niños y niñas acrecentar su autoría nativa es el no sesgar sus interpretaciones desde nuestros propios parámetros socioculturales y prejuicios (Behar, 1996; Fraser, Lewis, Ding, Kellett \& Robinson, 2004; Greene \& Hill, 2005; Podestá, 2004 y 2007; Rouch, 1995).

Las metodologías etnográficas participativas, que usan métodos visuales, resultan de suma utilidad para acercarse a esa condición. Han sido utilizadas cuando se trabajan temas sensibles como el de la discriminación, la inequidad, las diferencias de género y de raza (Bertely, 2004; Goulet \& Goulet, 2014; Podestá, 2007; Sartorello, 2016). Las metodologías participativas y decoloniales abren paso a la autoría nativa y la coteorización (Sartorello, 2016) como elementos para despojarnos de prejuicios dominantes y lograr entrar en otras epistemologías, en otras formas de conocer y aprehender el mundo.

\section{METODOLOGÍAS INDUCTIVAS INTERCULTURALES}

En este artículo nos posicionamos firmemente ante la necesidad de transitar hacia una interculturalidad de corte más crítico y colaborativo; esto es, entendemos la interculturalidad dentro de un marco de relaciones de dominación y sumisión padecidas por los pueblos indígenas, cuyo derecho a gestionar sus propias instituciones, recursos estratégicos y proyectos de desarrollo suele ser violado.

Desde esa concepción crítica, la educación intercultural debe avanzar hacia un proyecto político-pedagógico que contribuya a la decolonización y a la transforma-

ción de la sociedad y de su estructura de dominación. Por eso, si bien el foco de este 
artículo está puesto en experiencias indígenas particulares, la problemática de la interculturalidad y la decolonialidad reside también en los sectores no indígenas de la población, incluyendo a los blancos occidentales; es decir, no son categorías de una vía en que los actores subalternos de la sociedad, como pueblos indígenas, afrodescendientes y migrantes, son los únicos obligados a conocer la cultura y la epistemología dominante. Se trata de un proceso y proyecto que se construye "desde abajo", a partir de las aspiraciones y necesidades de las comunidades y, en este caso, pueblos indígenas en colaboración con académicos y especialistas no-indígenas.

Optar por esta alternativa exige recurrir a metodologías de trabajo que propicien la participación activa de todos los involucrados y faciliten que los educadores comunitarios, docentes de escuelas oficiales, los comuneros y los niños y las niñas pasen de ser los objetos de una investigación académica a los sujetos protagonistas de ella. Vale la pena aclarar que comunero es todo hombre o mujer titular de derechos agrarios en común con otros individuos o propietarios. El comunero goza de esa calidad por pertenecer al núcleo bajo el régimen comunal y satisfacer los requisitos que la ley y las disposiciones internas de la comunidad establecen.

Además de recopilar información sobre las necesidades y preferencias concretas de todos los actores, las metodologías deben funcionar como un medio para transformar sus procesos de pensamiento o subjetividades, y para generar y consolidar interaprendizajes. En otras palabras, deben vincularse a los locus de enunciación nativos y construidos localmente (Bertely, 2007). Este artículo propone tres metodologías colaborativas que han sido utilizadas en dos estudios de caso con la finalidad de explicar y sistematizar las experiencias. Antes de presentar ambos estudio de caso, es necesario hacer dos aclaraciones: por una parte, lo que entendemos por participación comunitaria y, por otra, de qué manera estas propuestas se insertan en una pedagogía decolonial contrapuesta a la educación multiculturalista de corte neoliberal y a la racionalidad occidental.

Sobre el primer punto, cabe mencionar que una de las metodologías que mejor ha conseguido comprender e impulsar los procesos participativos es la investigación-acción-participativa (Fals, 1979), que cuestiona la supuesta neutralidad y objetividad de los investigadores y propone que sean las personas afectadas por un problema quienes participen de manera activa en la investigación, creación de conocimiento e intervención sobre su realidad. Si bien entendemos las metodologías que abordaremos en la siguiente sección como investigación-acción-participativa enfocada al campo de la educación intercultural, consideramos que investigación-inductiva-intercultural (Bertely, 2017) es un nombre más adecuado, ya que facilita una exploración inductiva de la realidad al tiempo que interviene en la constitución de subjetividades.

En cuanto al segundo punto, consideramos que estas metodologías constituyen herramientas pedagógicas interculturales y decoloniales que cuestionan la lógica hegemónica de pensamiento que reproduce la colonialidad del poder y el saber. Se trata de estrategias que facilitan la intercomprensión entre los colaboradores indígenas y no indígenas a partir del uso de diferentes lenguajes en los que se plasman maneras distintas de ser, conocer, aprender y vivir. Los dos estudios de caso que ilustran estas tres metodologías y que a continuación describimos se ajustan a un modelo pedagógico intercultural para niñas y niños indígenas que construye interaprendizajes situados local e históricamente. Abarca, además, una dimensión política 
que se sustenta en la autodeterminación y el buen vivir como horizontes de lucha para la construcción de una ciudadanía étnica diferenciada caracterizada por los conocimientos y los valores positivos propios, entre los que destaca la integridad entre sociedad y naturaleza.

\section{USO DE DIBUJOS Y FOTOGRAFÍAS PARA LA AUTORÍA INFANTIL}

El material que se presenta en este estudio de caso forma parte de una investigación etnográfica escolar realizada en 2007 en una escuela primaria pública, de turno vespertino, ubicada en las periferias del municipio de Zapopan, Jalisco. Tomando como referencia los círculos de cultura en los que Paulo Freire se valía del dibujo para detonar el diálogo, optamos por utilizar dibujos y fotografías para conocer cómo van construyendo su identidad étnica los niños indígenas urbanos (Freire, 2000). No debemos olvidar que las culturas indígenas hacen un uso extensivo de imágenes y símbolos para expresar y preservar sus valores, sus rituales, sus conocimientos y, en general, su vida cotidiana. Por ello, resulta pertinente recoger, sistematizar y analizar la percepción propia de los niños y las niñas indígenas urbanos sobre su identidad étnica a través del dibujo.

Uno de los métodos empleados en un inicio fue el dibujo libre como canal de expresión cognitiva, afectiva y social de los niños. Durante el recreo escolar, niños y niñas llegaban a dibujar con crayones y en un solo papel grande cualquier cosa que quisieran. Esta actividad fue el pretexto perfecto para, poco a poco, conocerlos, que nos conocieran, y conocer fragmentos de sus mundos, sus familias, lo que más disfrutan y lo que les preocupa. Después de varios meses de convivencia durante los descansos, mientras dibujábamos en el piso o jugábamos "tazos", les sugerimos hacer dibujos de los pueblos de sus padres. Con este paso adelante en el trabajo queríamos que los niños y las niñas plasmaran sus costumbres, sus familias, su cotidianidad y todas aquellas representaciones simbólicas a partir de los cuales se identifican con un colectivo y que les ofrecen sentido de pertenencia étnica.

Para muchos de ellos, el tiempo del recreo no fue suficiente para llevar a cabo esta actividad y quisieron llevarse las hojas y los colores a sus casas. La semana siguiente recibimos dibujos de flores, campos abiertos y soleados, maíz, una gran diversidad de actividades al aire libre, el cuidado de animales, el disfrute de los ríos, el tiempo de ocio con la familia y muchas sonrisas. Esto coincide con los testimonios de muchos niños y niñas que platicaban durante las entrevistas del deseo de estar más tiempo en las comunidades, allá les parece más divertido, más relajado y se sienten más felices. Sin embargo, también comparten que en la ciudad, según lo que sus padres les dicen, hay más trabajo y es menos pesado físicamente para ellos. Además, los padres le dan gran peso a la escuela y a la importancia de que sus hijos aprendan para construir trayectorias de vida distintas a las de ellos. 

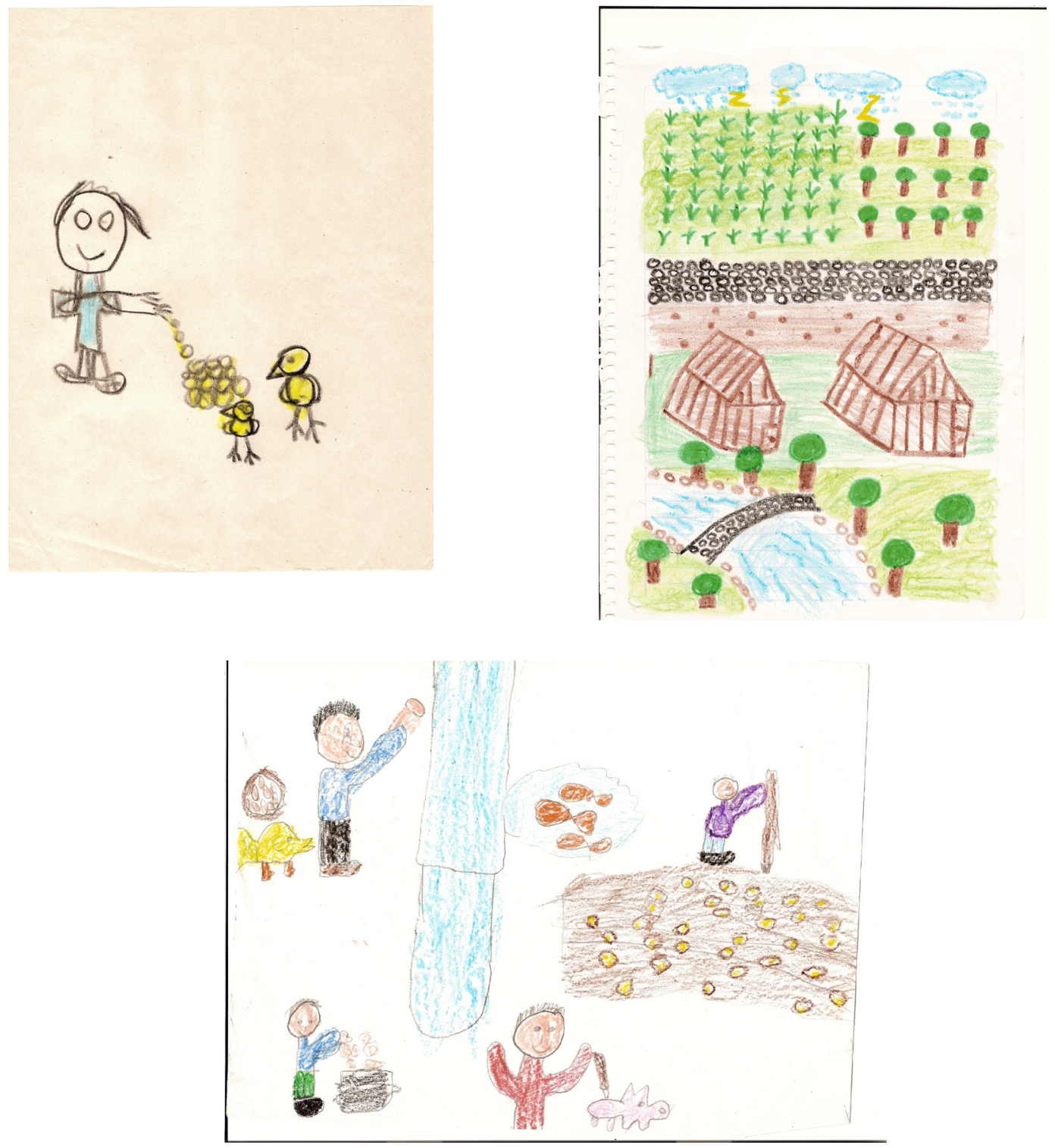


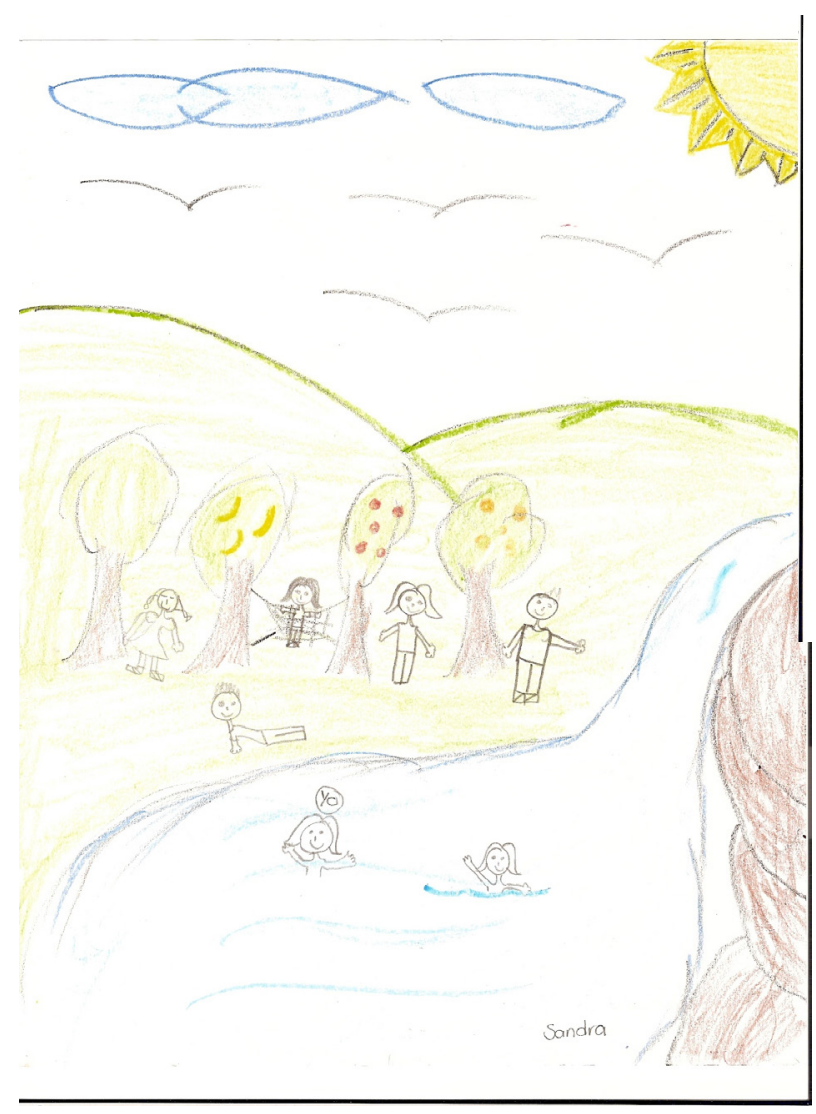

Meses después, en una segunda fase del trabajo, entregamos cámaras desechables para que tomaran fotografías de lo que ellos quisieran compartir, de los lugares que les gustaban y que no les gustaban de sus colonias, de las actividades que hacían habitualmente antes de llegar a la escuela y de todo aquello que querían mostrar a otros, de manera general. El uso de las fotografías fue, en este caso, una estrategia colaborativa de construcción de conocimiento situado y contextualizado. Favorece el desarrollo de pensamiento crítico y reflexivo, permite repensar sus propias prácticas, da cuenta de sus experiencias subjetivas en un plano emocional, social y personal, y reconoce la naturaleza situada socioculturalmente de los aprendizajes y la construcción del conocimiento (Spielman, 2001; Horwitz, 2012).

Después de una semana, los niños y las niñas nos devolvieron las cámaras, y volvimos días después con las fotografías reveladas para platicar con ellos. La posibilidad de iniciar diálogos a partir de imágenes concretas nos abrió nuevas posibilidades para entender el mundo en el que vive la niñez indígena urbana, como lo hizo Freire con las comunidades campesinas en Brasil. Vimos en la práctica cómo las entrevistas tradicionales son un medio neocolonizador que suele intimidar a la niñez y reproducir las relaciones asimétricas entre el entrevistador y el entrevistado (Apple, 1995; Giroux, 2001; Kincheloe \& McLaren, 2002; Scheurich, 1997; Weiler, 2001).

Hubo un caso en especial de un niño totonaco de sexto grado, Marcos, que visita la comunidad de sus padres cada verano para ayudar en las actividades agrícolas. Nos pidió si podía llevar la cámara para enseñarnos todo lo que hacía en su pueblo al lado de sus abuelos. A continuación, presentamos una muestra de algunas de las fotografías que nos compartió. 

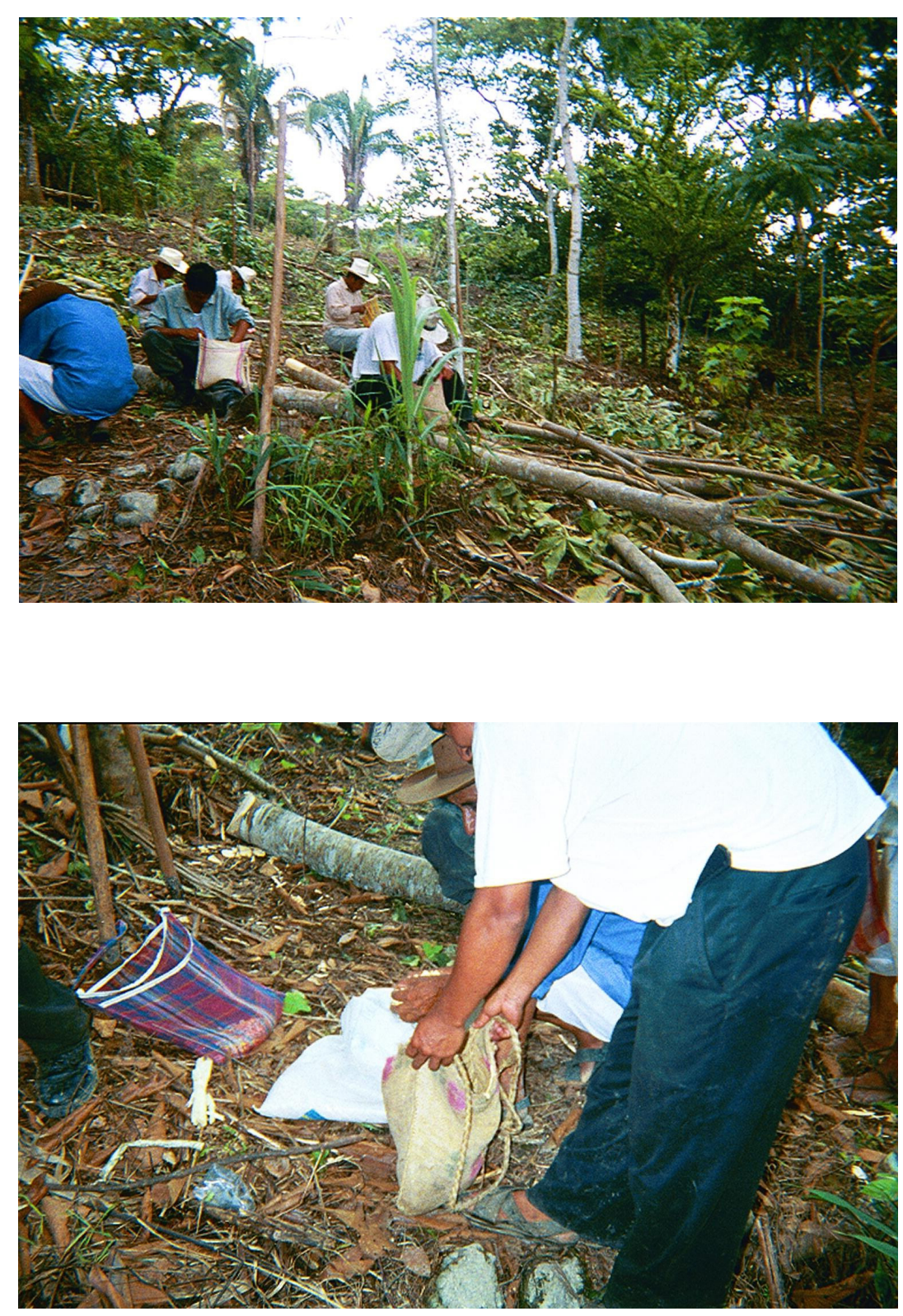

En estas dos primeras fotografías, Marcos retrató el territorio del que su familia es originaria y al que regresan a realizar actividades productivas y sociales. En esas actividades, que ocurren en el territorio socionatural, se encuentra implícito el modo de vida y la sabiduría que las comunidades comparten y que se materializa en relaciones, tensiones, celebraciones y rituales. El territorio, desde esta perspectiva, es el elemento de cohesión social y, en consecuencia, es identidad colectiva al permitir la articulación de un grupo con el espacio que reivindican como propio.

Aunque Marcos y sus padres emigraron de su territorio, no dejaron atrás su identidad étnica y en la ciudad recrean una colectividad cultural en que sus miembros comparten símbolos comunes, un mismo origen y relaciones de parentesco. Son, en este caso, comunidades extraterritoriales, conscientes de que la supervivencia de su grupo étnico, con todos sus valores positivos, sus conocimientos propios y su vida práctica pasa, necesariamente, por la defensa de la persistencia y la integridad de su territorio originario. 


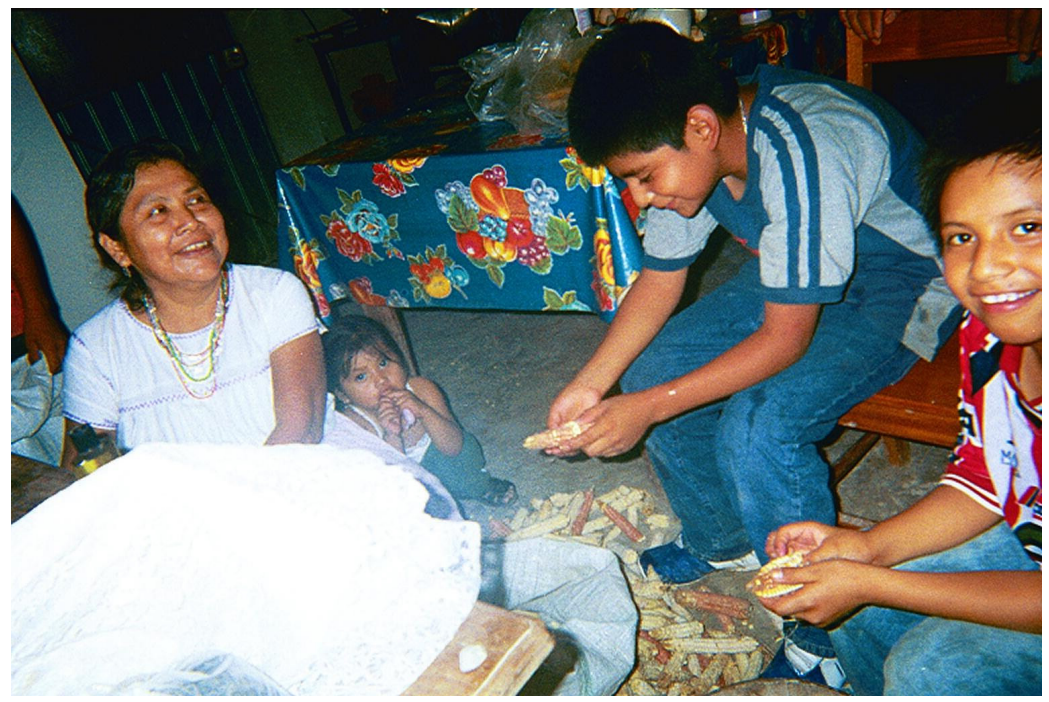

Esta imagen ilustra cómo el medio familiar de Marcos está fuertemente vinculado con el medio laboral, ya que muchas de las tareas requieren la cooperación de mujeres, hombres y niños en un mismo espacio y tiempo.

Sin afán de idealizar la vida comunitaria, aún es común encontrar en la sociedad rural e indígena afecto y placer por el trabajo cuando este es de autosustento, donde el comunero es dueño de su ritmo de trabajo, donde se trabaja en colectivo, y se convierte en espacio permanente de socialización. A pesar de vivir en la ciudad, donde esa condición no se cumple, Marcos y su familia la conservan y la reproducen cuando vuelven a su comunidad de origen.

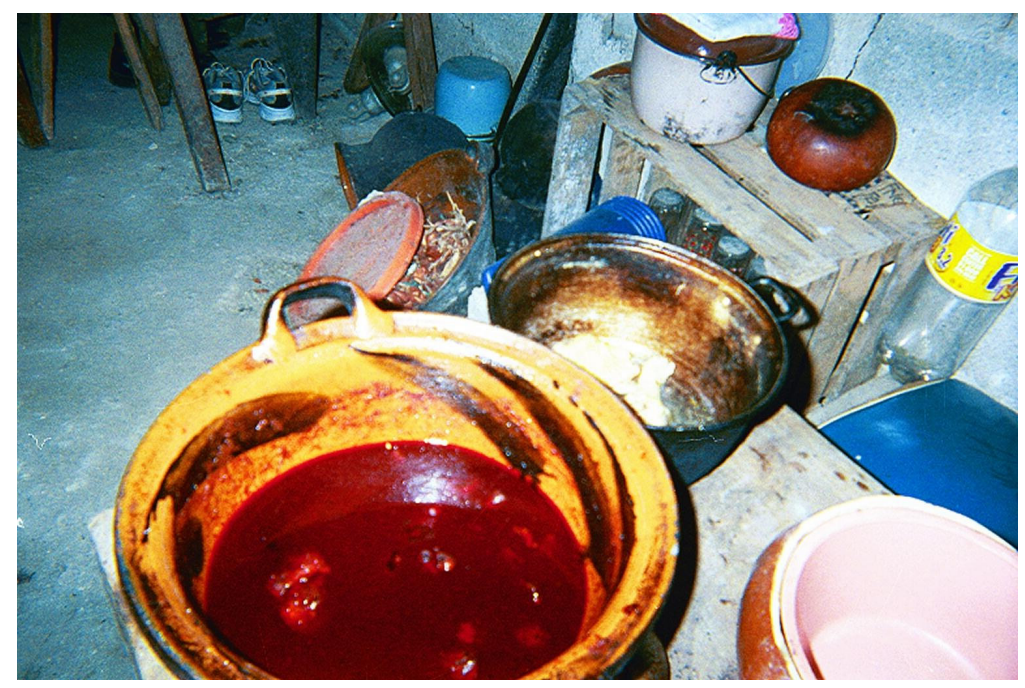




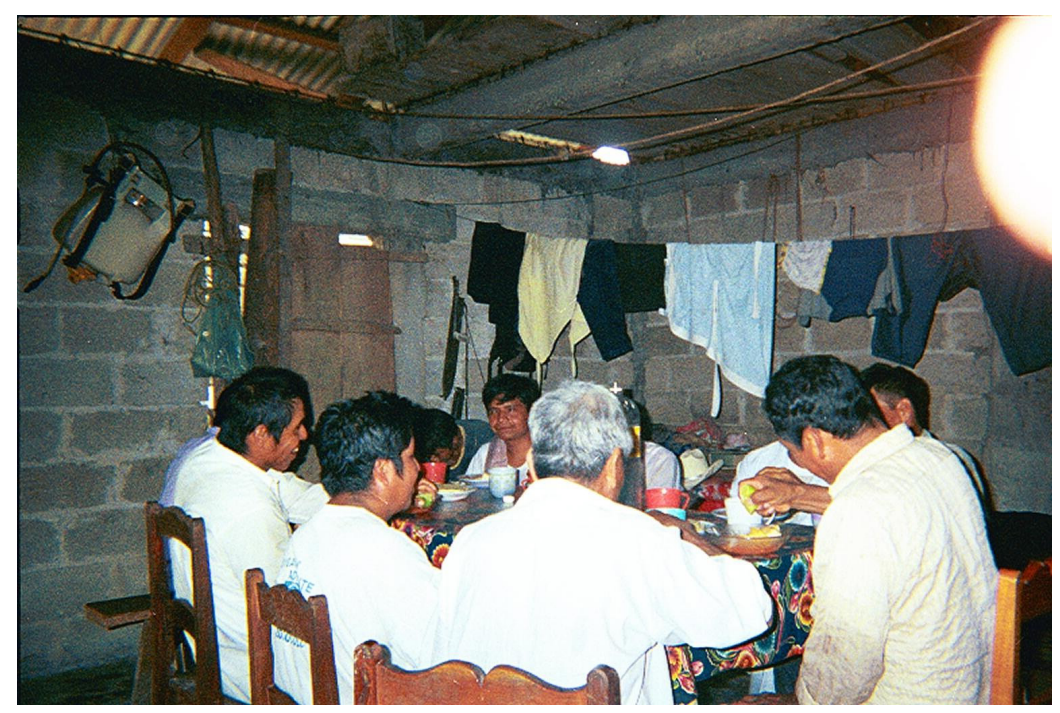

Estas dos últimas instantáneas muestran el momento de la comida como un acto social en el que la familia de Marcos comparte en la mesa el producto de su trabajo y encuentra ocasión para convivir y para fijar y estrechar lazos. En una comida en común, una familia, una comunidad, un grupo de amigos, manifiestan sus relaciones internas, su identidad individual o colectiva, su solidaridad, e incluso su historia porque los alimentos que toman suelen ser tradicionales de la región.

En suma, tanto los dibujos elaborados por los niños en la escuela como las fotografías capturadas por Marcos en la comunidad de sus padres ponen en cuestión la existencia de demarcaciones claras entre los indígenas rurales y urbanos. Por el contrario, expresan el carácter dinámico y cambiante de la etnicidad a partir de las relaciones familiares, grupales y laborales. Si bien la escolarización privilegia, en buena medida, la integración de las comunidades distintivas a la sociedad nacional, muchos indígenas migrantes continúan tejiendo redes de participación y solidaridad con los familiares y paisanos que decidieron permanecer en su comunidad. Tales relaciones permiten fundir su cotidianidad en la ciudad con la cotidianidad en el pueblo de origen de sus padres y, en algunos casos, revitalizar su lengua indígena.

Los dibujos y las fotografías dejan ver, por un lado, la dimensión cultural/simbólica de cohesión y arraigo que tiene el territorio para los niños indígenas migrantes, y, por otro, que, a pesar de que ellos y sus padres se han incorporado y participan plenamente en la dinámica citadina, muchos conservan y reconstruyen su identidad. Se trata de comunidades morales que se reproducen al interior de las familias, en la convivencia con los paisanos o bajo la orientación de una autoridad moral reconocida por todos.

El maestro de Marcos lo tenía en un concepto de tímido y callado en el salón de clases. Para Marcos, era importante "no meterse en problemas en la escuela", evitar los conflictos y cumplir cabalmente con lo que el profesor pedía. Siempre obtuvo buenas calificaciones y llegaba puntual a la escuela. Así, terminó la primaria y fue el promedio más alto de su grupo, aunque reconocía que sus profesores no enseñaban con la calidad que él esperaba; mencionó el absentismo y la falta de relevancia de las actividades de aprendizaje. Nos compartió que no le gustaba que le pusieran a copiar páginas completas del libro de texto al cuaderno y que no le explicaran en detalle cómo son las operaciones matemáticas. Varias veces nos compartió que este 
tema, de la falta de calidad en la escuela, se discute mucho entre los miembros de su familia, pero los papás le recomiendan sacar el mejor provecho posible de lo que tiene y de la importancia de cumplir el objetivo de obtener el certificado de primaria sin mayor problema.

Como vemos, fueron las fotografías por iniciativa de Marcos las que permitieron comenzar un diálogo mucho más profundo sobre su identidad indígena desde los temas que él consideraba importante compartir con el Otro. Territorio, alimentación y un conjunto de valores sociales, como el trabajo, la cooperación y la reciprocidad, forman parte sustancial de la experiencia vivencial que da lugar a la identidad étnica. Identidad y cultura aglutinan en la colectividad una cosmovivencia particular, una forma de conocimiento, una lengua, determinadas prácticas, relaciones, discursos y actitudes sociales.

\section{FOTOVOZ: UNA MIRADA DESDE LA COMUNIDAD}

El segundo estudio de caso que analizaremos es el proyecto colaborativo Milpas Educativas, que comenzó en 2017 y tiene como objetivo construir un modelo educativo intercultural multilingüe, pertinente y relevante a las prácticas culturales de las comunidades indígenas. El proyecto es coordinado desde el Instituto de Investigaciones para el Desarrollo de la Educación de la Universidad Iberoamericana, por Stefano Sartorello, y desde el Centro de Investigaciones y Estudios Superiores en Antropología Social (CIESAS), por María Bertely. El fundamento político, epistémico y pedagógico del proyecto es el método inductivo intercultural (MII), que desde hace más de veinte años ha sido contextualizado a la realidad de las regiones indígenas mexicanas por un grupo de educadores comunitarios mayas de Chiapas, algunos congregados en la Unión de Maestros de la Nueva Educación de México (UNEM) y otros autodefinidos como Educadores Independientes (Sartorello, 2016; Nigh y Bertely 2018). Además de Chiapas, se han instalado Milpas Educativas en diversas comunidades de Oaxaca, Michoacán y Puebla.

El término milpa se refiere al sistema ancestral de agricultura y manejo de recursos en el que se hacen plantaciones anuales en policultivo de maíz de gran altura combinado con frijol o haba, calabaza, magueyes, nopales y otros cultivos. En ese sentido, la Milpa Educativa hace referencia a los espacios educativos vivos dentro del territorio socionatural de una comunidad, donde tienen lugar las actividades sociales y productivas que, pedagogizadas, generan aprendizajes para el buen vivir.

Milpas Educativas habría de potenciar el interaprendizaje, y la recuperación y generación de conocimientos y prácticas relevantes y necesarios para construir el buen vivir para las comunidades involucradas, entendido como un trabajo para ir construyendo un ideal de vida colectivo. Sistematizar y verbalizar en colectivo esos interaprendizajes, conocimientos y prácticas cotidianos que caracterizan a la sociedad indígena es el primer paso para involucrar a la comunidad en la decisión de qué y cómo aprender, y sobre todo para trazar en comunidad su razón de vivir y de aprender (Bertely, 2007). A fin de cuentas, la propuesta educativa que se está construyendo en las Milpas Educativas tiene un componente etnopolítico que consiste en buscar la autodeterminación de los pueblos originarios y el ejercicio de una democracia activa y solidaria. 
El reto estaba en cómo explicar los conceptos, conocimientos y valores socionaturales propios relacionados con el buen vivir e implícitos en las actividades que las comuneras y los comuneros realizan en el territorio socionatural. La sistematización, en la que colabora uno de los autores de este artículo, exigía explorar y tratar de encontrar de manera inductiva las historias, voces y experiencias de los participantes sobre campos relacionados con la agroecología, la soberanía alimentaria, la alimentación sana, la salud comunitaria y los principios de una educación para la vida buena. Con todo ello en mente, la técnica de investigación elegida para recopilar evidencia del trabajo que se ha llevado a cabo en cada una de las milpas y de cómo opera el MII en dicho trabajo fue la llamada fotovoz.

La fotovoz es una técnica participativa que combina la fotografía con una narración del proceso y los aprendizajes que la misma fotografía sugiere. Los orígenes de esta metodología se remontan a Caroline Wang y otros colaboradores en la Escuela de Salud Pública de la Universidad de Michigan en la década de 1990. La crearon con la finalidad de dar voz y empoderar a las personas que suelen ser silenciados e invisibilizados con tal de que participen como agentes de cambio en su comunidad.

En palabras de sus creadores, la fotovoz consiste en que "los miembros de la comunidad tomen fotografías, contando historias; y al compartir su aprendizaje, informen a los responsables políticos sobre cuestiones de interés para la comunidad" (Wang, Cash \& Powers, 2000, p. 1). Entre los principios teóricos que fundamentan la fotovoz, cabe destacar la educación popular de Paulo Freire, la teoría feminista, que reivindica la apreciación subjetiva de la situación desde la perspectiva de lo subalterno y la fotografía documental desde la comunidad (Soriano y Cala, 2016).

En el caso de las Milpas Educativas, las fotovoces elaboradas debían hacer explícitos dos elementos fundamentales del trabajo por medio de las fotografías y las narrativas o historias que complementan las imágenes:

- Dado que de la vida práctica de las personas en su territorio específico deriva la visión sintáctica de la cultura que sustenta al MII (Gasché, 2008), esta sistematización tenía que explicar los cuatro ejes de la sintaxis cultural articulados en el enunciado genérico "Nosotros vamos a nuestro territorio a pedir un recurso que trabajamos en un objeto que tiene un fin social" y el eje transversal del significado indígena:

Territorio ("Nosotros vamos a nuestro territorio"; vamos a la milpa; vamos al río). Recurso natural ("pedir un recurso"; pedir maíz; pedir caracol).

Técnica o trabajo ("que trabajamos"; que cosechamos; que pepenamos).

Fin social ("para satisfacer un fin social"; para alimentar a nuestra familia; para comer un caldo sabroso).

Significado indígena (relatos míticos, cantos, oraciones, etcétera, que dan el sentido propio de cada pueblo a la actividad).

Son los comuneros mismos, que habitan el territorio, en compañía de educadores comunitarios y de niñas y niños, en interaprendizaje, los que documentarán con sus fotografías y palabras sus propias realidades y elaborarán el diagnóstico. 
- Las cuatro dimensiones que le dan a esta propuesta metodológica su actitud problematizadora permanente. El MII nos proporciona un horizonte crítico y una nueva manera de investigar para transformar la realidad:

Pedagógica, ya que las actividades productivas y sociales de la comunidad son el punto de partida de los procesos pedagógicos interculturales.

Política, porque su objetivo es la transformación social objetiva y subjetiva con miras a construir una ciudadanía diferenciada y una democracia activa.

Ontológica, es decir, aquella racionalidad "otra" desde la cual las comunidades indígenas entienden el mundo y donde la integración sociedad/naturaleza/ sobrenaturales es fundamental en sus discursos y su hacer en el territorio.

Axiológica, pues los fines y valores están orientados a la búsqueda de fortalecer el tipo de sociedad indígena que tiene a la solidaridad (distributiva, laboral, ceremonial) como rasgo genérico.

La intención al ampliar las reflexiones e interaprendizajes a estas cuatro dimensiones es que la sintaxis cultural no opere solo como una "red para pescar contenidos [escolares] de las actividades sociales" (AAVV, 2009, p. 95), sino que permita, además, pescar conocimientos territoriales y culturales que caracterizan a un tipo de sociedad diferente a la occidental. Una sociedad que tiene distintas nociones del tiempo, del espacio y de la naturaleza, y que establece otro tipo de relaciones con los otros seres humanos, con los seres espirituales y con los seres de la naturaleza. A continuación describimos los aspectos de cada una de las cuatro dimensiones que podían abordarse mediante la fotovoz.

Para la dimensión ontológica, la reflexión debe encaminarse hacia la integración sociedad-naturaleza, que es sin duda la característica distintiva de la sociedad indígena que procura una relación armoniosa con la naturaleza, que considera la madre. No habrá una buena vida, no se alcanzará el buen vivir si no hay armonía con la Madre Tierra que los cuida y los alimenta. Esta armonía sociedad-naturaleza se manifiesta en forma constante en las actividades cotidianas de la comunidad.

En cuanto a la dimensión política, la cuestión sobre la que consideramos necesario reflexionar con fotovoz fue la resistencia frente al avasallamiento del neoliberalismo y su modelo extractivista con acciones como la autosuficiencia, la soberanía alimentaria, la economía solidaria, la revalorización de los conocimientos comunitarios y las luchas étnico-territoriales y en defensa del territorio. Dentro de la dimensión axiológica, lo que destaca es la necesidad de conocer los fines y valores de una actividad específica, como son reciprocidad, respeto, autolimitación, solidaridad, generosidad, igualdad, pluriactividad y autonomía.

Como ya mencionamos, para la dimensión pedagógica, las fotovoces deben resaltar la relación entre el MII, la realización de la actividad concreta y el buen vivir. La fotovoz y la reflexión que esta detona debían concentrarse en el aporte de la actividad social, productiva, recreativa o ritual a la vida buena y las consecuencias que tendría dejar de practicarla. Además, debía mostrar qué impacto tendría en el modo de vida de la comunidad si dañamos alguno de los ejes de la sintaxis cultural del MII: si dañamos el territorio, si acabamos con alguno de los recursos naturales necesarios para la actividad, si nos olvidamos del trabajo y la técnica transmitida por los 
abuelos y los sustituimos por el trabajo fácil y la tecnología occidental o si dejamos de lado que nuestras actividades persiguen un fin social para satisfacer nuestras necesidades de manera autosuficiente y autogestiva.

El siguiente es un ejemplo de una fotovoz elaborada por uno de los educadores comunitarios que colaboran en el proyecto. Se trata de una secuencia de fotografías de una actividad con recursos que regala la milpa, en este caso, la elaboración de canastos de caña brava. Cada fotografía de la secuencia corresponde a un eje de la sintaxis cultural.

\section{TERRITORIO}

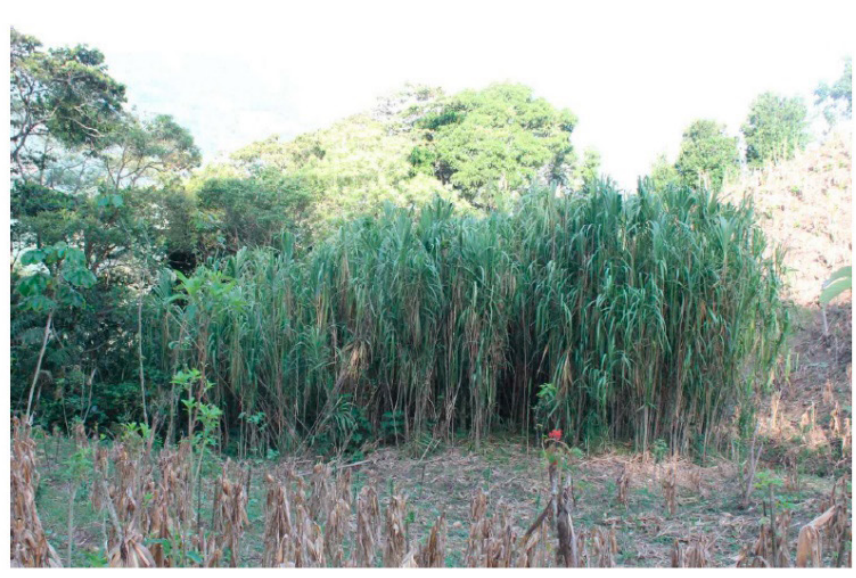

Para nosotros el suelo es muy sagrado porque nos aporta los alimentos de nuestra vida cotidiana... en este suelo húmedo no se siembra maíz, frijol y café porque no crecen, pero se puede sembrar la caña brava (taniw), muy útil para diferentes trabajos comunitarios. En la parte de arriba donde está la caña brava se encuentra el espacio donde se hace la milpa... no es monocultivo cuando se trabaja se vuelve policultivo trabajándolo sin abandonar para migrar a la ciudad en busca de empleo para vender nuestra fuerza de trabajo barato o esperar los proyectos que da el gobierno para destruirnos.

RECURSO NATURAL

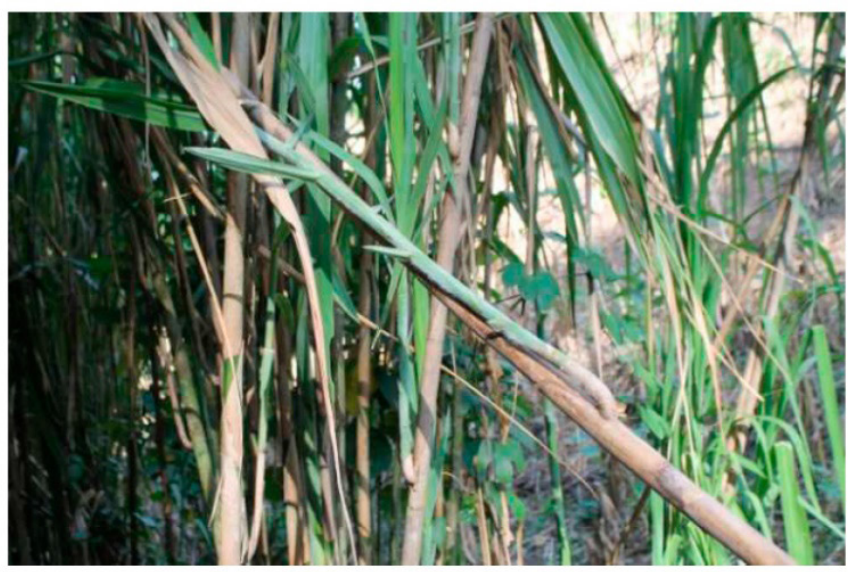

Para nosotros el suelo es muy sagrado porque nos aporta los alimentos de nuestra vida cotidiana... en este suelo húmedo no se siembra maíz, frijol y café porque no crecen, pero se puede sembrar la caña brava (taniw), muy útil para diferentes trabajos comunitarios. En la parte de arriba donde está la caña brava se encuentra el espacio donde se hace la milpa... no es monocultivo cuando se trabaja se vuelve policultivo trabajándolo sin abandonar para migrar a la ciudad en busca de empleo para vender nuestra fuerza de trabajo barato o esperar los proyectos que da el gobierno para destruirnos. 


\section{TRABAJO}

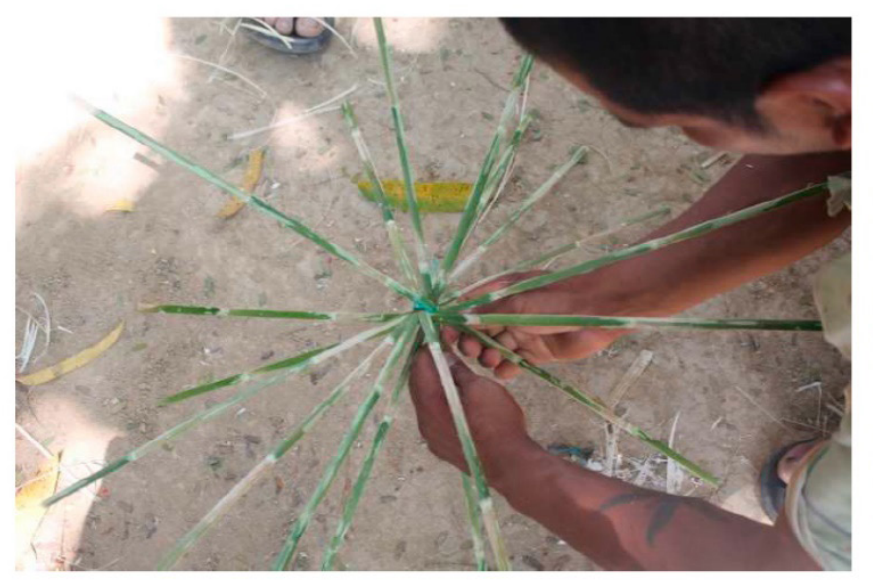

Este tipo de actividad se realiza por temporada de acuerdo el trabajo que marcan los meses del año... como dijo un joven comunero [al reflexionar sobre este trabajo] es mejor prepararnos en algo que satisface nuestra necesidad $y$, en este sentido, la actividad del canasto nos ejemplificó que haciendo solo es más tardado que en colectivo "komon a'telil". Usando lo que hay en nuestra región no se gasta dinero, se ahorra y también no se hace basura en la comunidad, menos contaminación para el ambiente.

FIN SOCIAL

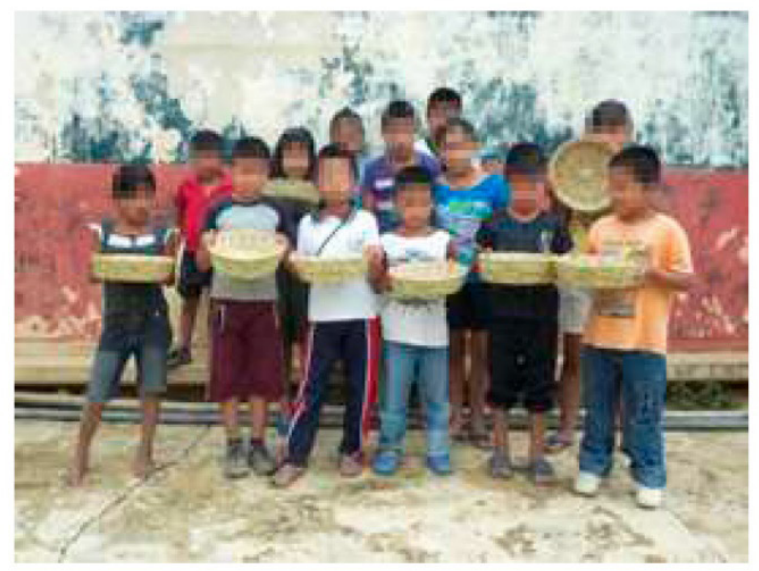

Nuestros abuelos han utilizado el canasto y ahora pocos son los que le están dando usos como para guardar el pan, tortillas, maíz, frijol, frutas y verduras, para cortar café, frijol, para desgranar el maíz. Cuando se rompe, se puede tirar afuera de la casa, porque no contamina el medio ambiente. Ya estando podrido se hace polvo, hoy en día se ha estado acabando, porque lo han estado sustituyendo con los plásticos que sí contaminan el medio ambiente.

\section{SIGNIFICADO INDÍGENA}

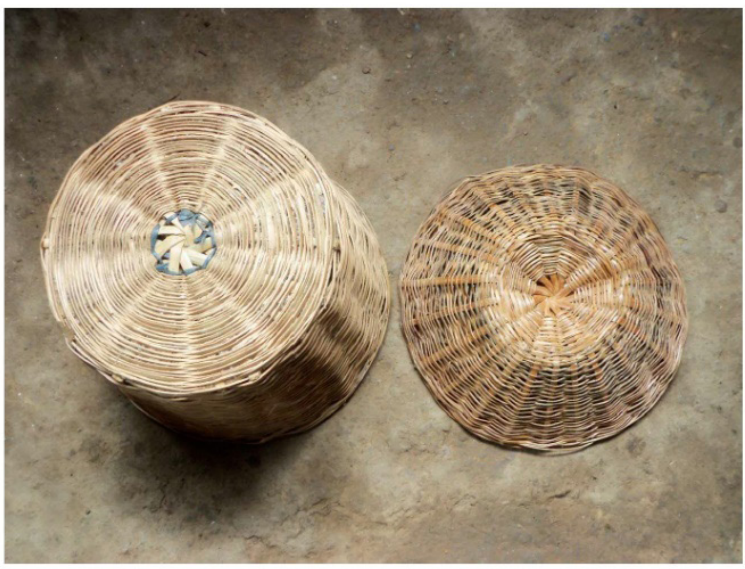

Nuestros abuelos y abuelas nos aconsejan de cómo prevenir los problemas y enfermedades que podremos enfrentar a futuras, tal es el caso sobre el uso del canasto; la caña brava seca o el desperdicio que sale de la caña brava para hacer el canasto no se puede quemar porque se seca la pata de los pollos, no come su masa se pone triste y se mueren. En el canasto no es bueno tapar los pollos porque le da reuma y se mueren también no es bueno darle a que incuban sus huevos las gallinas porque sale mal su pata los pollitos cuando nacen, también no es bueno tapar las gallinas culecas cuando están incubando sus huevos porque les da reuma, es así de cómo nuestros abuelos y abuelas nos enseñan con sus sabios consejos de que cada actividad que se realiza tiene sus significados propios que hay que tomarlo en cuenta y respetarlo. 
Aunque las Milpas Educativas cuentan con otros espacios de reflexión conjunta sobre los modos de aprender pertinentes y de compartir conocimientos que promueve el MII, con la fotovoz los educadores comunitarios, los comuneros y los niños y las niñas pueden realizar fotografías con narrativas colaborativas para dar su opinión sobre sus actividades pedagógicas y cómo mejorarlas. Sostenemos, entonces, que lo más importante de una metodología como fotovoz no es el producto en sí mismo, sino el proceso de reflexión y diálogo colectivo que ha de llevarnos a alcanzar nuestro objetivo común: mostrar nuestro trabajo para la salud, la autosuficiencia alimentaria y la vida en las Milpas Educativas.

\section{MAPAS VIVOS: UNA CARTOGRAFía PROPIA}

La tercera metodología que planteamos como alternativa a considerar por cualquier proyecto de pedagogía decolonial procede también de una línea de trabajo emergente que se ha construido colectivamente en Milpas Educativas con el propósito de ayudar a problematizar el territorio donde se ha instalado alguna milpa. En diversos talleres de interaprendizaje entre educadores comunitarios y académicos se discutió la necesidad de las comunidades de re-conocer su realidad espacial y social para poder defender sus derechos, descubrir conflictos y problemas de la comunidad, y generar acciones de resistencia territorial.

En concreto, en Milpas Educativas hemos optado por recurrir a los denominados "mapas vivos", una alternativa que la Red de Educación Inductiva Intercultural utilizó en la elaboración del cuaderno de trabajo Los hombres y las mujeres del maíz: democracia y derecho indígena para el mundo (Bertely, 2008). Se trata de un material de alfabetización ética, jurídica y territorial para los pueblos indígenas, aunque no exclusivamente. A diferencia de los mapas convencionales, que son elaborados por técnicos considerados expertos en la representación espacial, los mapas vivos son dibujos realizados con la participación colectiva de los sujetos locales que narran experiencias y actividades vivenciales en una comunidad. En el proceso de elaboración y en las reflexiones posteriores, los mapas vivos permiten construir conocimiento de manera colectiva y mezclar una variedad de saberes para dar cuenta de una imagen consensuada del territorio.

Como parte de un proyecto de educación intercultural desde una perspectiva crítica, los mapas vivos son una herramienta para descolonizar los saberes, pensares y haceres comunitarios. Permiten el re-conocimiento, representación y defensa del territorio que se habita y la visualización de formas de resistencia ante los problemas que se están dando debido al acaparamiento de tierras con grandes recursos naturales con base en el modelo extractivista; es decir, un mapa vivo permite investigar y comprender el contexto sociohistórico de una comunidad y articular sus problemáticas, que a primera vista parecen aisladas, pero que en realidad mantienen relaciones causales entre ellas. En particular, esta metodología ayuda a ir más allá de las descripciones y construir de manera gráfica la historia de los territorios, sus conflictos, los actores y sus relaciones, así como las amenazas y resistencias territoriales.

En concreto, se trata de un recurso que facilita a los miembros de una comunidad identificar y compartir los valores y los posicionamientos políticos que emergen en la vida cotidiana, de ahí que pueden adoptar distintas formas, dependiendo del objetivo que se persiga, por ejemplo: 
- Representar la cultura y los valores positivos de la sociedad indígena (reciprocidad, colectividad, respeto a los mayores, autosuficiencia).

-Visibilizar el contraste entre dos tipos de sociedad indígena/occidental (competencia, individualismo, corrupción).

-Mostrar las transformaciones del territorio a lo largo del tiempo:

a. Mapa del pasado para reconocer el territorio ancestral.

b. Mapa del presente con todos sus problemas socionaturales.

c. Mapa del futuro que muestre cómo quiere vivir y a dónde quiere llegar la comunidad.

- Mapeo de autoría nativa que sirva de material para una educación para el buen vivir; es decir, una propuesta didáctica que promueva la autosuficiencia y la relación integral con naturaleza.

Cualquiera de estos mapas constituye, en buena medida, una concepción del espacio indígena, que ha sido ignorado en los espacios de educación oficial en donde se han adoptado únicamente las convenciones cartográficas europeas. Se trata, entonces, de una estrategia que, además de la interculturalidad, promueve la decolonización y subversión del patrón de poder que incorpora la cartografía dominante, siempre en favor de la visión eurocéntrica (Galarza, 1991). Esta metodología participativa y subversiva convierte los mapas en la palabra y voz de las comunidades y representa en ellos la complejidad que se vive en sus territorios desde la diversidad de sus propias vivencias. Para ello, es necesario embarcarse en procesos de investigación y transformación social para construir de manera inductiva una representación colectiva del territorio como espacio geográfico y como contenedor de relaciones e interacciones.

Otro de los fines pedagógicos de esta herramienta es potenciar el pensamiento crítico entre los comuneros participantes en las Milpas Educativas, así como las actitudes para gestionar su territorio y reivindicar su derecho a construir desde abajo su autonomía. Tal como nos recordó el levantamiento zapatista, los pueblos indígenas tienen la capacidad para resistir a esa dominación y disminuir la desigualdad cultural y política frente al Estado al tiempo que construyen su autonomía. El levantamiento del Ejército Zapatista de Liberación Nacional del 1 de enero de 1994 en Chiapas fue una rebelión contra el capitalismo y las formas jerárquicas, coercitivas y de explotación del Estado y en favor de la libertad, la justicia y la autonomía.

La resistencia no es, por supuesto, un fin en sí mismo, pues su objetivo es construir una democracia activa y liberadora a partir de la cual las comunidades indígenas puedan negociar y discutir con el Estado mexicano dentro de esas relaciones de dominación, pero teniendo como intermediario un liderazgo indígena sustentado jurídicamente y no las formas de intermediación propias del indigenismo oficial; es decir, para garantizar un diálogo intercultural en condiciones más justas y equitativas, ambos interlocutores deben ser conscientes de que son portadores de una historia política, una identidad cultural y una estructura organizativa diferentes. Esto sugiere la necesidad de trabajar la intraculturalidad, esto es, un diálogo al interior 
de cada comunidad y entre comunidades de un grupo etnolingüístico particular a fin de fortalecer estos componentes culturales; para ello, los mapas vivos pueden ser un instrumento muy útil.

Si la aspiración política de la propuesta educativa de la UNEM/Educadores Independientes y la Red de Educación Inductiva Intercultural es la autonomía, la formación de las niñas y los niños debe encaminarse a esta para construirla desde abajo. Esto no será posible desde la educación escolarizada y su concepción fragmentada de la cultura y que considera el conocimiento científico como el único válido; por lo tanto, los educadores deben poner al proyecto político de su comunidad por encima de los contenidos del currículo escolar. Más aún, su labor debe prever la formulación, en colectivo con los comuneros, de un proyecto étnico o plan de vida. Una cuestión fundamental a tener en cuenta es que no puede construirse autonomía sin conocer a fondo el territorio donde se ejercerá esa autonomía, no solo desde la información que aporta la geografía convencional, sino desde los aportes de una cartografía propia que caracterice al territorio en su sentido amplio e integral con sus dimensiones social, cultural, política y económica.

\section{CONCLUSIONES}

Las tres metodologías enunciadas aquí, en conjunto y de manera articulada, muestran cómo son los valores propios de las comunidades indígenas, cómo se manifiesta la relación sociedad-naturaleza-seres espirituales y cómo se organizan las comunidades como ciudadanos y ejercen sus derechos. ¿Qué actividades realizamos y qué relaciones establecemos para construir una vida ética y ciudadana buena y saludable? En otras palabras ¿cómo tejemos y hacemos comunidad para sembrar un buen vivir como alternativa a los proyectos de desarrollo y muerte?

Es importante que las fotovoces sirvan como evidencia de los interaprendizajes ocurridos en una actividad y, además de explicar la sintaxis cultural de la actividad, sean herramientas didácticas sobre los valores positivos y negativos de una comunidad, el territorio, su cuidado y su defensa, así como sus derechos y obligaciones. Valores como la reciprocidad, el respeto, el acuerdo y la resistencia son fundamentales para cuidar el territorio, organizarse y resolver conflictos. Solo fortaleciendo y difundiendo estos valores podemos ser más resistentes ante el poder egoísta que nos despoja, nos humilla y transforma nuestra forma de ver el mundo. En suma, la fotovoz puede ser también un retrato del modo de ser y el pensamiento indígena que respeta los ritmos y tiempos de la naturaleza y que construye una vida digna con base en el trabajo, la cooperación y la solidaridad.

Los mapas vivos, por su parte, son una fuente de reflexión sobre problemáticas y situaciones locales que involucran a la comunidad: docentes, familias, niños y niñas, abuelos y abuelas y miembros de la comunidad. Nos referimos a cuestiones como cuidado del territorio, importancia de los ojos de agua, manantiales y lugares sagrados, contaminación, propiedad de la tierra, formas de gobierno y concelebración de fiestas.

Por otro lado, los fines pedagógicos de las fotovoces promueven un sentido distinto de la educación intercultural. Ponen en evidencia la polifonía, la comprensión del mundo desde un punto de vista interepistémico que permite dar cuenta de saberes que no son los hegemónicos o los que el currículo escolar defiende. 
Estas metodologías fomentan el diálogo y no el aprendizaje vertical y, además, promueven que las distintas culturas conozcan otros modos de vida y otra forma de luchar y ejercer los derechos. Son materiales que resultan pertinentes para una educación fundamentada en el MII, ya que a diferencia de los libros de texto convencionales que reproducen el conocimiento desde la abstracción, explican ese conocimiento territorial, ético y jurídico desde la experiencia viva de las prácticas y las relaciones sociales.

Los diferentes lenguajes que se articulan en materiales como estos (visual, oral, escrito) permiten ir más allá de pensar en las condiciones objetivas y materiales de nuestra realidad, e invitan también a transformar subjetividades de quienes ven, escuchan, leen y sienten estos valores compartidos por los otros y otras. Son lenguajes que están al alcance de todos y todas; son democráticos, no requieren una escolarización impuesta por un Estado; son una posibilidad de abrirnos a nuevos saberes y solo así crear nuevas formas de relacionarnos y reconfigurarnos; son realizados desde abajo y de manera colaborativa, sin imposiciones académicas y con resultados muchas veces fuera del control de los proyectos de investigación.

\section{REFERENCIAS BIBLIOGRÁFICAS}

AAVV (2009). Modelo curricular de educación intercultural bilingüe UNEM. En M. Bertely (ed.). Sembrando nuestra educación intercultural como derecho: diálogos, experiencias y modelos educativos de dos organizaciones indígenas del estado de Chiapas. Ciudad de México: UNEM/ECIDEA/CIESAS/IIAPOEI/ Alcatraz.

Apple, M. (1995). Education and power. Nueva York/Londres: Routledge.

Behar, R. (1996). The vulnerable observer, anthropology that breaks your heart. Boston: Beacon Press.

Bertely, M. (2017, 20-24 noviembre). Simposio de la Escuela a la Milpa Educativa: Tensiones y negociaciones intra e interculturales en la gestión y desarrollo de un proyecto educativo para el buen vivir. México.

Bertely, M. (2013). Debates conceptuales sobre educación multicultural e intercultural. En M. Bertely Busquets, G. Dietz y M. G. Díaz Tepepa (eds.). Multiculturalismo y educación 2002-2011 (pp. 41-80). México: COMIE.

Bertely, M. (ed.) (2008). Los hombres y mujeres del maíz. México: UNEM.

Bertely, M. (2007). Lecciones éticas y ciudadanas de los Pueblos Mayas para el mundo. Filosofía política y metodologías de un proyecto educador. Revista de Antropología Social, vol. 16, pp. 213-244. Recuperado de http://www.redalyc.org/articulo.oa?id=83811585008

Bertely, M. (2004). Nuestros pueblos de hoy y siempre. El mundo de las niñas y los niños nahuas en México a través de sus propias letras y dibujos de Rossana Podestá. Revista Mexicana de Investigación Educativa, vol. IX, núm. 20, pp. 153-157.

Dietz, G. (2003). Multiculturalismo, interculturalidad y diversidad en educación. Una aproximación antropológica. México: Fondo de Cultura Económica.

Esteva, G. (2015). Para sentipensar la comunalidad. Bajo el Volcán, vol. 15, núm. 23, pp. 171-186. Recuperado de http://www.redalyc.org/articulo. oa?id=28643473010 
Fals Borda, 0. (1979). El problema de cómo investigar la realidad para transformarla por la praxis. Bogotá: Tercer Mundo Editores.

Fornet-Betancourt, R. (2000). Interculturalidad y globalización. Ejercicios de crítica filosófica intercultural en el contexto de la globalización neoliberal. Frankfurt: IKO.

Fraser, S., Lewis, V., Ding, S., Kellett, M. \& Robinson, C. (eds.) (2004). Doing research with children and young people. Londres: Sage.

Freire, P. (2000). Pedagogy of the opressed. Nueva York: Continuum.

Galarza, J. (1991). Lienzos o mapas aztecas. Manuscritos pictóricos mexicanos de contenido cartográfico. Chicomoztoc, vol. 3, pp. 5-27. Recuperado de http://www.descolonizacion.unam.mx/pdf/Ch3_2_Lienzos.pdf

García León, D. L. y García León, J. E. (2014). Educación bilingüe y pluralidad: reflexiones entorno de la interculturalidad crítica. Cuadernos de Lingüística Hispánica, núm. 23, pp. 49-65. Recuperado de http://www.redalyc.org/articulo.oa?id=322229950004

Gasché, J. (2010). De hablar de la educación intercultural a hacerla. Mundo Amazónico, vol. 1, pp. 111-134. Recuperado de https://centroderecursos.cultura. pe/es/registrobibliografico/de-hablar-de-la-educaci\%C3\%B3n-intercultural-hacerla

Gasché, J. (2008). Niños, maestros, comuneros y escritos antropológicos. En M. Bertely, J. Gasché y R. Podestá (eds.). Educando en la diversidad cultural (pp. 279-366). Quito: Abya Yala.

Giroux, H. (2001). Theory and resistance in education: Towards a pedagogy for the opposition. Westport: Bergin \& Garvey.

Goulet, L. \& Goulet, K. (2014). Teaching each other. Nehinuw concepts \& indigenous pedagogies. Vancouver: UBC Press.

Greene, S. \& Hill, M. (2005). Conceptual, methodological and ethical issues in researching children's experiences. En S. Greene \& D. Hogan (eds.). Researching children's experience. Approaches and methods (pp. 1-21). Londres: Sage Publications.

Horwitz, (2012). Photovoice as a critical reflection methodology. En R. Flessner et al. Agency through teacher education: Reflection, community and learning (pp. 15-25). Lanham, MD: Rowman \& Littlefield Publishers.

Kincheloe, J. \& McLaren, P. (2002). Rethinking critical theory and qualitative research. En E. Trueba \& Y. Zou (eds.). Ethnography and schools. Qualitative approaches to the study of education (pp. 87-138). Lanham, MD: Rowman and Littlefield Publishers, Inc.

Nigh, R. \& Bertely, M. (2018). Conocimiento y educación indígena en Chiapas, México: un método intercultural. Diálogos sobre Educación, año 9, núm. 16.

Podestá, R. (2007). Encuentro de miradas: el territorio visto por diversos autores. Niñas, niños del campo y de la ciudad. México: Secretaría de Educación Pública-CGEIB.

Podestá, R. (2004). Otras formas de conocernos en un mundo intercultural. Revista Mexicana de Investigación Educativa, vol. 9, núm. 20, pp. 129-150. Recuperado de http://www.redalyc.org/articulo.oa?id=14002008

Rouch, J. (1995). The camera and man. En P. Hocking (ed.). Principles of visual anthropology. Berlin y Nueva York: Mouton de Gruvter. 
Scheurich, J. (1997). Research method in the postmodern. Londres: The Falmer Press.

Soriano, E. y Cala, V. (2016). Fotovoz: un método de investigación en ciencias sociales y de la salud. Madrid: La Muralla, SA.

Spielman, J. (2001). The family photograpy project: "We will just read what the pictures tell us". The Reading Teacher, vol. 54, núm. 8, pp. 762-770.

Sartorello, S. (2016). La co-teorización intercultural de un modelo educativo en Chiapas, México. Quito: Editorial Abya-Yala.

Walsh, C. (2013a). Lo pedagógico y lo decolonial. Entretejiendo caminos. En C. Walsh (ed.), Pedagogías decoloniales. Prácticas insurgentes de resistir, (re) existir y (re) vivir vol. I (pp. 23-68). Quito: Abya-Yala.

Walsh, C. (ed.) (2013b). Pedagogías decoloniales. Prácticas insurgentes de resistir, (re)existir y (re)vivir, vol. I. Quito: Ediciones Abya-Yala.

Wang, C., Cash, J. \& Powers, L. (2000). Who knows the streets as well as the homeless? Promoting Personal and Community Action through Photovoice. Health Promotion Practice, vol. 1, núm. 1, pp. 81-89. Recuperado de https:// journals.sagepub.com/doi/10.1177/152483990000100113

Weiler, K. (ed.) (2001). Feminist engagements. Reading, resisting and revisioning Male Theorist in Educational and Cultural Studies. Nueva York: Routledge. 